\title{
INKAR AL-SUNNAH DI INDONESIA (Studi Analisis Tentang Pemikiran Inkar al-Sunnah Ir. M. Ircham Sutarto)
}

\author{
CACA HANDIKA ${ }^{1}$ \\ Program Pasca Sarjana UIN Sunan Gunung Djati Bandung \\ e-mail: cacahandika98@gmail.com
}

\begin{abstract}
The history of the development of the hadith has recorded discussion of the inkar al-Sunnah. One of the causes of this movement is the occurrence of political differences among the Muslims which causes them to split into several groups or sects (firqah). The existence of this article is to discuss inkar al-Sunnah in the contemporary period III in Southeast Asia, namely Indonesia-Malaysia, but in this paper only discusses the inkar al-Sunnah in Indonesia and focuses on Ircham Sutarto's thoughts about inkar al-Sunnah. Al-Qur'an and al-Sunnah are sources of Islamic teachings that must become guidelines for human life. But in practice there are still people who deny al-Sunnah and only accept the Qur'an which is absolutely narrated mut mutually. This study aims to determine the character and teachings of inkar al-Sunnah in Indonesia, namely the thinking of Ircham Sutarto. This study uses a library study methodology, which in conducting the research a researcher is confronted with various written literatures which are the primary sources in this study and according to the object of the study. The core of this research reveals some teachings or understandings of one of the incarcerated figures of al-Sunnah in Indonesia, namely Ir. M. Ircham Sutarto, who totally rejected al-Sunnah. One of the teachings of the inkar al-Sunnah Ircham Sutarto which is contained in a dictate which he wrote himself by hand said that the hadith was limited to a fairy tale or the story of the Prophet brought and told by people who lived 180 to 200 years after the Prophet Muhammad died and the story was lets be a fake story (fictitious). In his teachings also said that before getting a revelation all humans have been lost and also included in the Prophet including Muhammad never lost, in accordance with the QS. AlBaqarah [2]: 198. According to him also that the Prophet had no right to rule over humans in religious matters and carry it out, in accordance with the proposition of the QS. Al-Imran verse 228 translation of his version that is, "There is no (haq) authority for you in matters of command at all."
\end{abstract}

Keywords: Hadith, Indonesia, Inkar al-Sunnah, Ircham Sutarto

\begin{abstract}
Abstrak
Sejarah perkembangan hadits telah mencatat adanya pembahasan mengenai inkar al-Sunnah. Salah satu penyebab adanya gerakan ini dengan terjadinya perbedaan politik di kalangan kaum muslimin yang menyebabkan mereka terpecah menjadi beberapa golongan atau sektesekte (firqah). Adanya tulisan ini untuk mendiskusikan inkar al-Sunnah pada periode kontemporer III di Asia Tenggara yaitu Indonesia-Malaysia, akan tetapi dalam tulisan ini hanya dibahas mengenai inkar al-Sunnah yang ada di Indonesia dan terfokus pada pemikiran Ircham Sutarto tentang inkar al-Sunnah. Al-Qur'an dan al-Sunnah merupakan sumber ajaran Islam yang harus menjadi pedoman bagi kehidupan manusia. Akan tetepi pada prakteknya masih ada orang-orang yang mengingkari al-Sunnah dan hanya menerima al-Qur'an yang mutlak diriwayatkan secara mutawatir. Penelitian ini bertujuan untuk mengetahui tokoh dan
\end{abstract}


ajaran inkar al-Sunnah yang ada di Indonesia yaitu pemikiran Ircham Sutarto. Penelitian ini menggunakan metodologi studi kepustakaan atau library resesarch yang mana dalam pelaksanaan penelitiannya seorang peneliti dihadapkan dengan berbagai literartur tertulis yang menjadi sumber primer dalam penelitian ini dan sesuai objek kajiannya. Inti dari penelitian ini mengungkap beberapa ajaran atau paham dari salah satu tokoh inkar al-Sunnah di Indonesia yaitu Ir. M. Ircham Sutarto yang menolak secara keseluruhan mengenai al-Sunnah. Salah satu ajaran faham inkar al-Sunnah Ircham Sutarto yang terdapat dalam diktat yang beliau tulis sendiri dengan tulisan tangan mengatakan bahwa hadits itu hanya sebatas dongeng atau cerita Nabi yang dibawa dan diceritakan oleh orang yang hidup 180 sampai 200 tahun setelah Nabi Muhammad wafat dan cerita itu memungkinkan menjadi cerita palsu (fiktif). Dalam ajarannya juga mengatakan bahwa sebelum mendapatkan wahyu semua manusia itu pernah tersesat dan juga didalamnya termasuk Nabi Muhammad pernah tersesat, sesuai dengan QS. Al-Baqarah [2]: 198. Menurut beliau juga bahwa Nabi itu tidak ada hak untuk memerintah kepada manusia dalam hal beragama dan menjalankannya, sesuai dengan dalil QS. Al-Imran ayat 228 terjemahan versi beliau yaitu, "Tidak ada (haq) wewenang bagi kamu dalam urusan perintah sedikitpun."

Kata Kunci: Hadits, Indonesia, Inkar al-Sunnah, Ircham Sutarto

\section{PENDAHULUAN}

Sejarah mengenai perkembangan hadits di dunia Islam telah mencatat adanya sebuah peristiwa yang sangat tidak asing lagi di telinga kita yaitu peristiwa Inkar al-Sunnah. Iinkar al-Sunnah merupakan sebuah faham yang menolak keberadaan al-Sunnah atau hadits sebagai sumber ajaran Islam setelah al-Qur'an, ${ }^{1}$ baik itu secara keseluruhan, sebagian maupun sesuai dengan periwayatan imam tertentu yang dianutnya. Peristiwa ini diawali dengan adanya perbedaan politik di kalangan umat Islam terdahulu sampai kepada puncaknya yang menyebabkan terpecah belahnya kaum muslimin ke dalam beberapa kelompok, golongan atau sekte-sekte (firqah). Dari peristiwa itulah munculnya golongan yang memiliki pemikiran tentang inkar al-Sunnah atau yang mengingkari tentang adanya hadits nabi.

Golongan tersebut merupakan golongan-golongan yang berbeda pendapat dengan ulama sunni dan sering juga disebut dengan al-mubtadi'. Dalam peristiwa inkar al-Sunnah terbagi ke dalam beberapa kategori di berbagai tempat, dari mulai dunia Arab sampai ke tanah air Indonesia tercinta.

Salah satu dari sekian banyak aliran inkar al-Sunnah yang berkembang di dunia Islam adalah inkar al-Sunnah yang berkembang pada periode kontemporer III di Asia Tenggara

\footnotetext{
hlm. 141

${ }^{1}$ Relit Nur Edi, As-Sunnah (Hadits) (Suatu Kajian Aliran Ingkar Sunnah), (Asas: 2014), Vol. 6, No. 2 ,
} 
yaitu di Indonesia-Malaysia. Di Asia Tenggara itulah banyak sekali melahirkan orang-orang yang mempunyai pemikiran tentang paham inkar al-Sunnah yang sampai saat ini masih mereka pertahankan karena keyakinannya tentang inkar al-Sunnah. Dengan adanya peristiwa seperti itu setidaknya bisa mengganggu keimanan dan keyakinan seseorang (khususnya orang yang tidak terlalu paham agama) terhadap sumber ajaran Islam (khususnya Hadits Nabi Muhamad Saw).

Dalam tulisan ini hanya satu peristiwa yang akan dibahas tentang peristiwa inkar alSunnah pada periode kontemporer III yaitu paham inkar al-Sunnah di Indonesia menurut salah satu tokoh yaitu pemikiran inkar al-Sunnah Ircham Sutarto. Hal ini dilakukan untuk menghindari ketidakfokusan dalam pembahasan dan agar pembahasannya lebih mendalam dan spesifik.

Dengan demikian, fokus dalam tulisan ini lebih kepada pemahaman Ircham Sutarto mengenai inkar al-Sunnah serta ajaran-ajarannya mengenai yang beliau sebarkan ke beberapa pengikutnya.

Paham inkar al-Sunnah selalu identik dengan dunia Arab yang banyak orang menyangka bahwa dunia Arab lebih bisa memahami dan mengamalkan hadits atau sunnah dibandingkan dengan negara-negara lain yang non Arab. Padahal kalau kita perhatikan dan pelajari sejarah perkambangan hadits dari zaman ke zaman, bahwa inkar al-Sunnah itu tidak hanya terjadi di belahan dunia Arab atau Timur Tengah saja, akan tetapi jauh lebih itu sudah merambat ke tanah bagian Asia, salah satunya di Asia Tenggara yaitu Indonesia dan dalam tulisan ini terbukti bahwa ada aliran inkar al-Sunnah di Indonesia dan tokohnya.

Penganut Agama Islam di Indonesia sampai saat ini masih menduduki angka mayoritas dibandingkan dengan penganut agama-agama lain yang ada Indonesia. ${ }^{2}$ Hal itu membuktikan bahwa tingkat kepercayaan atau keyakinan masyarakat Indonesia terhadap agama Islam dan ajarannya yang tercantum dalam al-Qur'an dan al-Sunnah sangat tinggi, sehingga menyebabkan mereka untuk bisa menjalankannya tanpa paksaan atau intimidasi dari pihak manapun.

Hal itu terjadi secara turun temurun dari nenek moyang atau leluhur mereka masingmasing dan didukung oleh banyaknya sekolah-sekolah yang berbasis agama Islam di Indonesia. Akan tetapi di tengah-tengah mayoritas umat Islam di Indonesia, masih saja terjadi penyimpangan-penyimpangan yang signifikan dalam hal mereka beragama, yaitu salah

\footnotetext{
${ }^{2}$ Dari jumlah penduduk 224 juta jiwa, 89\% diantaranya adalah beragama Islam. Lihat Ahmad Zainuri, Keberagaman Komunitas Muslim dan Islam Ke-Indonesiaan, (Medina-Te: 2017), Vol. 16, No. 1, hlm. 1
} 
satunya dalam hal mempercayai salah satu sumber ajaran Islam (Sunnah) yang sering kita istilahkan dengan adanya paham inkar al-Sunnah.

Dengan demikian, perlu kiranya kita ketahui yang sesungguhnya mengenai faham inkar al-Sunnah tersebut dengan cara kita bahas dalam tulisan ini. Dengan kita mengetahui faham tersebut, minimal kita mengetahui dan tidak terjerumus ke dalamnya. Lebih jauh dari itu, kita bisa meminimalisir adanya perkembangan faham tersebut di Indonesia dengan cara mengarahkannya ke arah yang lebih baik sesuai dengan ajaran Islam yang terkandung dalam al-Qur'an dan al-Sunnah tanpa sedikitpun diinkari isinya. Dengan adanya penelitian ini kita bisa mengetahui isi pemahaman dari salah satu tokoh inkar al-Sunnah di Indonesia (Ircham Sutarto).

Realitanya ada sebuah perbedaan antara al-Qur'an dan al-Sunnah dalam hal segi periwayatan. Al-Qur'an seluruhnya diriwayatkan secara mutawatir dan mutlak harus diterima. Tetapi tidak semua hadits diriwayatkan secara mutawatir. ${ }^{3}$ Maka dari itu perlu adanya penelitian untuk menghindari pengingkaran terhadap al-Sunnah yang diriwayatkan secara mutawatir dan termasuk hadits shahih.

Penelitian ini bertujuan untuk mengetahui tokoh dan ajaran inkar al-Sunnah di Indonesia supaya kita tidak terjerumus ke dalamnya.

Penelitian ini bersifat kulaitatif, ciri-ciri dari penelitian kualitatif adalah pengamatan, wawancara, atau penelaahan dokumen. ${ }^{4}$ Salah satu ciri dari penelitain kualitatif yang penulis ambil yaitu menghimpun beberapa sumber atau dokumen yang berkaitan dengan fokus penelitian dan menelaah serta menelitinya. Teknik atau cara pengumpulan data yang digunakan dalam penelitian ini menggunakan studi kepustakaan (library research) yang terfokus pada sumber tertulis saja. Library research juga sering diartikan dengan sebuah penelitian yang dilakukan di perpustakaan dan dihadapkan dengan beberapa literatur yang ada sesuai dengan masalah yang dihadapi dalam penelitian tersebut. ${ }^{5}$ Kemudian, data yang dikumpulkan dari beberapa sumber dianalisis sesuai dengan kebutuhan penelitian sampai pada akhirnya dibuat sebuah kesimpulan penelitian.

Metodologi merupakan sebuah komponen yang sangat penting dalam dunia penelitian, karena sukses atau tidaknya sebuah penelitian dilihat dari sisi metodologinya. Dengan adanya

\footnotetext{
${ }^{3}$ Syuhudi Ismail, Metodologi Penelitian Hadits Nabi (Cet.I; Jakarta: PT. Bulan Bintang, 1992), h. 3

${ }^{4}$ Lexy J. Moleong, Metodologi Penelitian Kualitatif (Cet. XXIX; Bandung: Remaja Rosdakarya, 2011), h. 9

${ }^{5}$ Mantra Ida Bagoes, Filsafat Penelitian dan Metode Penelitian Sosial (Yogyakarta: Pustaka Pelajar, 2007), h. 40
} 
metodologi juga pembaca bisa mengetahui dan memahami cara kerja seorang peneliti dari mulai proses sampai menemukan sebuah kesimpulan penelitian. Dengan demikian, kehadiran metodologi sangat penting dalam penelitian.

Metode atau metodologi merupakan suatu cara atau teknik, yang ditempuh seseorang dalam melakukan sesuatu. Metodologi penelitian merupakan suatu cara atau teknik ilmiah yang digunakan seorang peneliti untuk mendapatkan data dari suatu permasalahan dengan tujuan dan kegunaan yang sudah ditentukan. ${ }^{6}$

\section{HASIL DAN PEMBAHASAN}

Paham inkar al-Sunnah tidak hanya berkambang di dunia Timur Tengah saja, akan tetapi sudah tersebar ke berbagai belahan dunia bagian Asia Tenggara yaitu ke negara Indonesia. Paham inkar al-Sunnah muncul di Indonesia sudah lama, kira-kira sejak tahun 1980-an, menurut seorang peneliti bahwa inkar al-Sunnah lahir di Indonesia itu sejak tahun 1982-1983. ${ }^{7}$ Dengan demikian, usia inkar al-Sunnah di Indonesia bukanlah hal yang baru, akan tetapi sudah lama da tua bersemayam di negeri ini. Bahkan ada yang mengatakan bahwa inkar al-sunnah atau inkar hadits di Indonesia sudah ada sejak tahun 1978 yang membuat

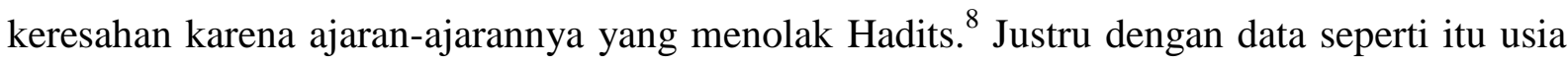
paham inkar al-Sunnah di Indonesia tidak muda lagi.

Paham inkar al-sunnah merupakan sebuah faham yang bisa merusak akidah seseorang dalam hal meyakini sumber ajaran Islam (al-Qur'an dan al-Sunnah) yang selama ini kita yakini. Orang yang menganut paham inkar al-Sunnah menganggap bahwa hadits merupakan kebohongan semata yang berasal dari Nabi Muhammad Saw., dan al-Qur'an lah menjadi satusatunya ajaran Islam yang harus dipegang oleh umat Islam sebagai pedoman hidupnya. ${ }^{9}$ Hal ini sangat berbahaya jika terus-terusan berkembang di Indoensia, karena bisa merusak otak dan akidah anak bangsa sekaligus para penerus agama Islam kedepannya. Padahal kalau dipikiran dengan akal sehat dan keimanan yang kuat, Hadits itu merupakan seluruh tindakan yang dihasilkan dari diri Nabi Muhammad untuk melahirkan sebuah hukum dan menjadi penjelas bagi al-Qur'an sendiri.

\footnotetext{
${ }^{6}$ Sugiyono, Metode Penelitian Kuantitatif Kualitatif dan R\&D (Cet. III; Bandung: Alfabeta, 2007), h. 2

${ }^{7}$ Abdul Majid Khon, Paham Ingkar Sunnah di Indonesia (Stdusi tentang Pemikirannya) (Jurnal Teologia: 2012), Vol. 23, No. 1, h. 57

${ }^{8}$ Nurfajriyani, Ingkar Hadits di Indonesia dan Malaysia: Studi Kritis Pemikiran Hadits Nazwar Syamsu dan Kassim Ahmad, (Tesis UIN Sunan Kalijaga, Yogyakarta: 2015), h. vii

${ }^{9}$ Nurfajriyani, Ingkar Hadits di Indonesia dan Malaysia: Studi Kritis Pemikiran Hadits Nazwar Syamsu dan Kassim Ahmad, h.vii.
} 
Paham inkar al-Sunnah harus diberantas secara habis jangan sampai tersisa. Faham inkar al-Sunnah ini kebanyakan terjadi di kalangan akademisi, karena mungkin mereka mempunyai pemikiran yang bebas, dengan kebebasan berpikir itulah mereka kebablasan dalam berfikir. ${ }^{10}$ Dengan demikian, perlu diwaspadai pemikiran-pemikiran di kalangan akademisi yang notabene mereka mempunyai kebebasan dalam berpikir (bukan berarti su'udzon dan menuduh), jangan sampai dengan kebebasan itu mereka kebablasan dalam mengungkapkannya. Meskipun bisa dikatakan bahwa inkar al-Sunnah yang terjadi di kalangan akademisi itu bukan sesuatu yang final. Akan tetapi, hal itu bisa jadi menjadi dasar ketika terjun ke masyarakat nantinya.

Kita sering membayangkan bahwa yang namanya paham inkar al-Sunnah ialah suatu faham yang secara total menolak akan hadirnya hadits atau sunnah. Akan tetapi, Daud Rasyd mengklasifikasikan bahwa paham inkar al-Sunnah di Indonesia dibagi menjadi tiga bagian, yaitu: Inkar al-Sunnah secara keseluruhan, inkar al-Sunnah sebagian dan inkar al-Sunnah selain menurut cara yang diriwayatkan. ${ }^{11}$ Inkar al-Sunnah secara keseluruhan merupakan sebuah paham inkar al-Sunnah di Indonesia yang dalam ajarannya hanya menerima al-Qur'an dan menolak Sunnah. Paham inkar al-Sunnah ini dipimpin oleh Muhammad Irham Sutarto. ${ }^{12}$ Inkar al-Sunnah sebagian adalah sebuah paham inkar al-Sunnah yang dalam pelaksanaannya tidak seluruh hadits itu ditolak, akan tetapi ada hadits-hadits yang diterima. Misalnya Haditshadits tentang akidah, muamalah' dan nikah. Dan juga ada beberapa Hadits yang ditolaknya yaitu hadits tentang alam ghaib. ${ }^{13}$ Sedangkan faham inkar al-Sunnah selain melalui cara yang diriwayatkan adalah sebuah faham yang hanya menerima hadits-hadits yang diriwayatkan melalui sanad yang bersambung kepada pimpinan golongannya dan smapai kepada Nabi Muhammad Saw. Akan tetapi, Hadits yang diriwayatkan oleh golongan lain, maka ditolaknya. $^{14}$

Berbicara mengenai paham inkar al-Sunnah di Indonesia, maka ada salah satu tokoh paham inkar al-Sunnah yang terkenal yaitu Ir. M. Ircham Sutarto dengan ulasan dibawah ini:

\section{Biografi}

Beliau merupakan Ketua dari kelompok Serikat Buruh Perusahaan Unilever Indonesia di Cibubur, Jawa Barat. ${ }^{15}$ Beliau juga sebagai pimpinan dari golongan ahli Qur'an atau

\footnotetext{
${ }^{10}$ Khoridatul Mudhiiah, Pemikiran Daud Rasyd Terhadap Upaya Ingkar Sunnah Kelompok Orientalis di Indonesia, Jurnal Addin, 2013, Vol. 7, No. 2, h. 431

${ }^{11}$ Khoridatul Mudhiiah, Pemikiran Daud Rasyd Terhadap Upaya Ingkar Sunnah Kelompok Orientalis di Indonesia, Jurnal Addin, 2013, Vol. 7, No. 2, h. 445

${ }^{12}$ Khoridatul Mudhiiah, Pemikiran Daud Rasyd Terhadap Upaya Ingkar Sunnah Kelompok Orientalis Di Indonesia, Jurnal Addin, 2013, Vol. 7, No. 2, h.. 446

${ }^{13}$ Khoridatul Mudhiiah, Pemikiran Daud Rasyd Terhadap Upaya Ingkar Sunnah Kelompok Orientalis Di Indonesia, Jurnal Addin, 2013, Vol. 7, No. 2, h. 448

${ }^{14}$ Khoridatul Mudhiiah, Pemikiran Daud Rasyd Terhadap Upaya Ingkar Sunnah Kelompok Orientalis Di Indonesia, Jurnal Addin, 2013, Vol. 7, No. 2, h. 448

${ }^{15}$ Zarkasih, Inkar Sunah: Asal Usul dan Perkembangan Pemikiran Inkar Sunah di Dunia Islam, Jurnal Toleransi, Media Ilmiah Komunikasi Ummat Beragama: 2012, Vol. 4, No. 1, h. 12
} 
Qur'aniyyun. ${ }^{16}$ Berhubung beliau sebagai ketua Serikat Buruh Perusahaan Unilever Indonesia, maka beliau mempunyai peran yang sangat besar dalam penyebaran faham inkar al-Sunnah di Indonesia dan beliau juga orang yang pertama menulis diktat dengan tulis tangan. Dalam tulisan itu hanya menggunakan dalil-dalil al-Qur'an yang memberikan keyakinan kepada kita bahwa beliau memang secara terang-terangan menolak adanya sunnah sebagaimana disebutkan di atas, dan beliau juga hanya menerima al-Qur'an sebagai pedoman hidupnya.

Di samping itu, juga beliau itu sebagai penggagas adanya aliran paham inkar al-Sunnah pasca kemerdekaan di Indonesia bersama Abdul Rahman, Nazwar Syamsu dan Dalimi Lubis. ${ }^{17}$ Mengenai beredarnya buku diktat tulisan beliau juga pemerintah mengeluarkan surat larangan beredar melalui SK no: KEP/J.A/9/1983. ${ }^{18}$

\section{Ajaran-ajaran}

Ada beberapa ajaran paham inkar al-Sunnah Ir. M. Ircham Sutarto terdapat dalam diktat yang ditulis tangan di atas, meskipun pada dasarnya diktat tersebut belum selesai dan belum diberi nama. Diantara ajaran-ajaran yang ditulis oleh Ir. M. Ircham Sutarto dalam diktat tersebut adalah sebagai berikut: ${ }^{19}$

a. Keterangan al-Qur'an itu ada dalam al-Qur'an itu sendiri, jadi tidak perlu menggunakan al-Sunnah untuk menjelaskan al-Qur'an. Dengan demikian al-Qur'an itu berdiri sendiri.

b. Semua keterangan yang datang dari luar al-Qur'an itu hawa, maka al-Sunnah itu bersifat hawa dan tidak dapat dijadikan sebagai hujjah dalam menentukan sebuah hukum.

c. Hadits merupakan dongeng Nabi Muhammad dari mulut ke mulut yang didapat dari orang yang hidup 180 sampai 200 tahun setelah Nabi wafat, maka dengan demikian hadits itu sulit untuk diterima karena informasinya belum jelas.

d. Menurut beliau bahwa Rasul atau Nabi itu tidak mempunyai hak dalam memerintah masalah agama dan hal itu didasarkan pada QS. Al-Imran ayat 128 terjemahan versi beliau yaitu, "Tidak ada (haq) wewenang bagi kamu dalam urusan perintah sedikitpun."

e. Semua manusia pernah tersesat sebelum mendapatkan wahyu dan termasuk juga Nabi Muhammad Saw. Dalilnya terdapat dalam QS. Al-Baqarah [2]: 198 "Dan ingatlah

\footnotetext{
${ }^{16}$ Khoridatul Mudhiiah, Pemikiran Daud Rasyd Terhadap Upaya Ingkar Sunnah Kelompok Orientalis di Indonesia, h. 445

${ }^{17}$ Ali Maulida, Inkar al-Sunnah dari Kalangan Muslim dalam Lintasan Sejarah, Jurnal At-Tdabbur: tt, h. 146

${ }^{18}$ Ali Maulida, Inkar al-Sunnah dari Kalangan Muslim dalam Lintasan Sejarah, Jurnal At-Tdabbur: tt, h. 146

${ }^{19}$ Abdul Majid Khon, Paham Ingkar Sunnah di Indonesia (Studi tentang Pemikirannya), h. 59-60
} 
kepadanya seperti yang telah kami tunjukkan kepadamu dan sesungguhnya kamu (Muhammad) sebelumnya benar-benar orang tersesat."

f. Taat kepada Allah, sedangkan Allah itu ghaib. Begitupun taat kepada Rasulullah sedangkan Rasulullah telah wafat. Maka dengan demikian tidak ada alasan untuk taat dalam arti yang sebenarnya terhadap keduanya.

g. Al-Qur'an merupakan ucapan Allah dan Rasul-Nya, dan mentaati atau menjalankan kehdiupan sesuai dengan al-Qur'an pun sudah merupakan arti taat kepada Allah dan Rasul-Nya.

Sedikitnya ada tujuh ajaran paham inkar al-Sunnah Irchm Sutarto yang penulis temukan, akan tetapi mungkin saja dalam prakteknya masih banyak faham-faham lain yang dianut oleh Ircham Sutarto dalam mengingkari al-Sunnah karena beliau merupakan salah satu tokoh yang mengingkari al-Sunnah secara keseluruhan.

Beberapa alasan tentanga pengingkaran al-Sunnah yang dilakukan oleh Ir. M. Ircham Starto menulis penulis itu keluar dari keyakinan kita (umat muslim) tentang beragama Islam, khususnya dalam meyakini bahwa al-Qur'an dan al-Sunnah itu merupakan satu kesatuan yang bisa dipisahkan sebagai sumber utama ajaran Islam dan al-Sunnah menduduki posisi penting setelah al-Qur'an.

Dikatakan bahwa penjelasan yang ada dalam al-Qur'an itu sudah ada dalam al-Qur'an itu sendiri dan itu memang adanya, lalu tidak perlu adanya al-Sunnah untuk menjelaskan alQur'an. Akan tetapi hal itu tidak semua dijelaskan dalam al-Qur'an itu sendiri, tapi terdapat dalam Hadits. Sebagaimana firman Allah dalam QS. An-Nahl [16]: 44 :

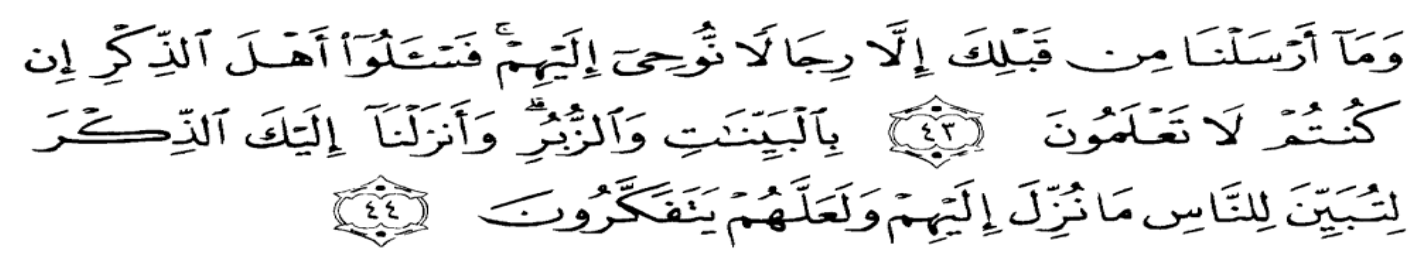

Terjemahnya :

Keterangan-keterangan (mukjizat) dan kitab-kitab. Dan Kami turunkan kepadamu Al-Quran, agar kamu menerangkan pada umat manusia apa yang telah diturunkan kepada mereka dan supaya mereka memikirkan. ${ }^{20}$

Allah menurunkan al-Qur'an itu tiada lain kepada Nabi Muhammad dan dalam ayat tersebut Nabi Muhammad diperintahkan oleh Allah untuk menjelaskan maksud al-Qur'an itu kepada

${ }^{20}$ Ahmad Fachruddin, dkk., Al-Qur'an Digital Versi 2.0, (Software: 2004), QS. An-Nahl [16]: 44 
manusia yang lain. Secara otomatis hal yang keluar dari dalam diri Nabi (baik itu ucapan, perbuatan, peretujuan) termasuk kedalam Hadits atau al-Sunnah. Dengan merujuk kepada ayat al-Qur'an di atas tidak mungkin al-Sunnah itu diingkari keberadaannya. Selain ayat alQur'an di atas ada juga ayat lain yang bisa kita gunakan untuk mengritik paham inkar alSunnah Ircham Sutarto yang menganggap bahwa al-Qur'an tidak memerlukan Hadits dalam penjelasannya yaitu QS. Al-Hasyr [59]: 7 yaitu :

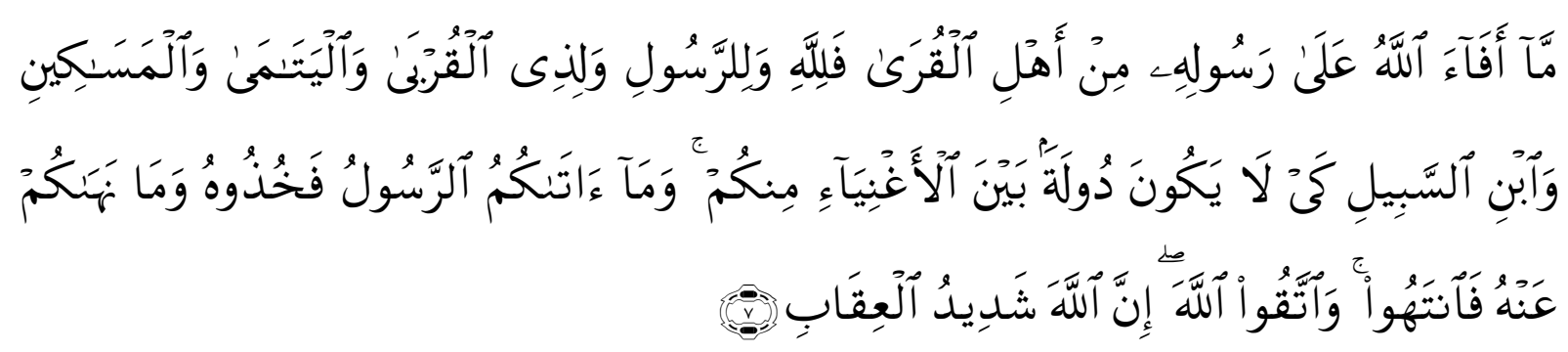

Terjemahnya :

Apa saja harta rampasan (fai-i) yang diberikan Allah kepada RasulNya (dari harta benda) yang berasal dari penduduk kota-kota Maka adalah untuk Allah, untuk rasul, kaum kerabat, anak-anak yatim, orang-orang miskin dan orang-orang yang dalam perjalanan, supaya harta itu jangan beredar di antara orang-orang Kaya saja di antara kamu. apa yang diberikan Rasul kepadamu, Maka terimalah. dan apa yang dilarangnya bagimu, Maka tinggalkanlah. dan bertakwalah kepada Allah. Sesungguhnya Allah Amat keras hukumannya. ${ }^{21}$

Eksistensi al-Hadits itu memang sangat penting dalam kehidupan khususnya dalam menjelaskan al-Qur'an dan tidak boleh diingkari keberadaannya. Selanjutnya Ircham Sutarto mengatakan bahwa Hadits itu merupakan dongeng-dongeng Nabi dari mulut ke mulut dan dibawa oleh orang yang hidup 180 sampai 200 tahun setelah Nabi wafat. Pemehaman ini sangat keliru, karena sebagaimana kita ketahui seperti para sahabat yang hidup sejaman dengan Nabi Muhammad itu banyak yang meriwayatkan hadits dari beliau, misalkan kita contohkan mereka adalah khulafa ar-rasyidin. Mungkin yang Ircham Sutarto maksudkan adalah sebuah ceita yang dibuat-buat untuk kepentingan masing-masing kelompoknya, misalkan ketika terjadi perang politik antara kaum Sunni dan Syi'ah dan disitulah terjadi kemunculan hadits-hadits palsu serta pada masa pemerintah Umar bin Abdul Aziz adanya pengkodifikasian Hadits karena untuk mengurangi tersebarnya hadits-hadits palsu yang dibuat oleh pelaku bid'ah. ${ }^{22}$

\footnotetext{
${ }^{21}$ Ahmad Fachruddin, dkk., Al-Qur'an Digital Versi 2.0, (Software: 2004), QS. Al-Hasyr [59]: 7

${ }^{22}$ Luthfi Maulana, Periodisasi Perkembangan Studi Hadits (Dari Tradisi Lisan/Tulisan hingga Berbasis Digital), Jurnal Esensia: 2016), Vol. 17, No. 1, hlm. 111
} 
Sebatas pelayakan penulis, Ircham Sutarto juga mengalami kekeliruan dalam mengartikan sebuah ayat yang dimana dimaksudkan bahwa Nabi Muhammad tidak ada hak untuk ikut campur dalam masalah perintah keagamaan yang beliau artikan dari QS. Al-Imran [3]: 128. Padahal kalau kita lihat dari beberapa terjemahan al-Qur'an bahwa "Tidak ada sedikitpun campur tanganmu dalam urusan mereka itu, atau Allah menerima taubat mereka atau mengazab mereka karena semua mereka itu orang-orang yang dzalim. ${ }^{, 23}$ Terjemahan senada hampir sama dengan terjemahan dalam Mushaf al-Qur'an dan terjemahannya yaitu, "Itu bukan menjadi urusanmu Muhammad, apakah Allah menerima taubat mereka atau mengazabnya, karena sesungguhnya mereka orang-orang dzalim. "24 Dengan demikian tidak sepantasnya Ircham Sutarto mengartikan sebagaimana di atas.

Penulis kira semua pemahaman yang dibawa oleh Ircham Sutarto mengenai paham inkar al-Sunnah dapat kita kritik dengan dasar keyakinan kita terhadap al-Qur'an dan al-Sunnah sebagai sumber ajaran Islam dan hal itu tidak bisa dielakan dalam menjalani kehidupan ini.

\section{PENUTUP}

Dari pemaparan di atas mengenai paham inkar al-Sunnah di Indonesia yang dibawa oleh Ir. M. Ircham Sutarto adalah sebuah paham inkar al-Sunnah yang dalam ajarannya menolak seluruh al-Sunnah yang dinyatakan dalam Hadits Nabi Muhammad saw. dengan berbagai alasan yang beliau kemukakan dalam sebuah diktatnya. Karena inkar al-Sunnah sering kita maksudkan kepada suatu kepercayaan atau paham yang mengingkari dengan adanya hadits atau al-Sunnah. Pengingkarannya itu ada yang mengingkari secara keseluruhan, ada yang mengingkari sebagian dan ada juga yang hanya menerima periwayatan lewat orang yang sekelompok dengannya. Semua ajarannya tersebut sangat bertolak belakang dengan kepercayaan dan keyakinan umat Islam terhadap al-Qur'an dan al-Sunnah yang menjadi sumber ajaran Islam dan pedoman bagi hidup manusia.

Menurut pandangan beliau bahwasanya Hadits atau al-Sunnah itu merupakan dongeng-dongeng Nabi dari mulut ke mulut yang dibawa oleh orang yang hidup 18- sampai 200 tahun setelah Nabi Muhammad wafat. Beliau juga berpendapat bahwa semua orang itu pernah tersesat sebelum menerima wahyu dan hal itu termasuk Nabi Muhammad pembawa

${ }^{23}$ Ahmad Fachruddin, dkk., Al-Qur'an Digital Versi 2.0, QS. Al-Imran [3]: 128. Lihat keterangan ayat dalam software ini bahwa menurut Riwayat Bukhari bahwa turunnya ayat ini karena Nabi Muhammad berdo'a kepada Allah untuk menyelamatkan sebagian pemuka-pemuka musyrikin dan membinasakan sebagian yang lainnya.

${ }^{24}$ As-Sobar Qur'an, Al-Qur'an dan Terjemahannya, (Pustaka al-Mubin, Jakarta: 2013), h. 66 
hadits (al-Sunnah) pernah tersesat, seingga sulit ketika ucapan, perbuatan dan persetujuannya (hadits) dijadikan sebagai sumber hukum Islam. Disamping itu beliau juga sangat mengagungkan al-Qur'an dengan mengatatakan bahwa penjelasan al-Qur'an itu sudah ada dalm al-Qur'an itu sendiri sehingga dalam penjelasannya tidak membutuhkan hadits yang diyakini mayoritas umat muslim sebagai penjelas bagi al-Qur'an.

Akan tetapi semua pandangan dan paham dan ajaran beliau mengenai inkar al-Sunnah yang ada dalam diktatnya dapat penulis (khususnya umat Islam) kritisi dengan dasar keyakinan terhadap al-Qur'an dan al-Sunnah sebagai sumber utama ajaran Islam.

\section{DAFTAR PUSTAKA}

Ali Maulida. (t.t). Inkar al-Sunnah dari Kalangan Muslim dalam Lintasan Sejarah, Jurnal AtTadabbur.

Bagoes, Mantra Ida. (2007). Filsafat Penelitian dan Metode Penelitian Sosial. Yogyakarta: Pustaka Pelajar.

Fachruddin, Ahmad, dkk. (2004). Al-Qur'an Digital Versi 2.0, Software.

Ismail, Syuhudi. (1992). Metodologi Penelitian Hadits. Jakarta: PT. Bulan Bintang.

Khon, Abdul Majid. (2012). Paham Ingkar Sunnah di Indonesia (Studi tentang Pemikirannya), Jurnal Teologia. Vol. 23, No. 1.

Maulana, Luthfi. (2016). Periodisasi Perkembangan Studi Hadits (Dari Tradisi Lisan/Tulisan hingga berbasis Digital), Jurnal Esensia. Vol. 17, No. 1.

Mudhiiah, Khoridatul. (2013). Pemikiran Daud Rasyd Terhadap Upaya Ingkar Sunnah Kelompok Orientalis Di Indonesia, Jurnal Addin. Vol. 7, No. 2

Nur Edi, Relit. (2014). As-Sunnah (Hadits) (Suatu Kajian Aliran Ingkar Sunnah), Jurnal Asas. Vol. 6, No. 2.

Nurfajriyani. (2015). Ingkar Hadits di Indonesia dan Malaysia: Studi Kritis Pemikiran Hadits Nazwar Syamsu dan Kassim Ahmad, Tesis UIN Sunan Kalijaga, Yogyakarta.

Qur'an, As-Sobar. (2013). Al-Qur'an dan Terjemahannya. Jakarta: Pustaka al-Mubin.

Zainuri, Ahmad. (2017). Keberagaman Komunitas Muslim dan Islam Ke-Indonesiaan, Jurnal Medina-Te. Vol. 16, No. 1.

Zarkasih. (2012). Inkar Sunah: Asal Usul dan Perkembangan Pemikiran Inkar Sunah di Dunia Islam, Junal Toleransi, Media Ilmiah Komunikasi Ummat Beragama, Vol. 4, No. 1. 